\title{
Feature Optimization on Dual Leap Motion Controller for Indonesian Sign Language
}

\author{
Syaiful Nugraha*, Rachmat, Teddy Istanto, Agus Prayitno \\ Department of Informatics, Musamus University, Merauke, Indonesia
}

\begin{abstract}
Sign language is a language formed by a combination of finger, hand, body movements and facial expressions used by persons with disabilities such as deaf and speech impaired. One of these sign language recognitions is recognition using Leap Motion Controller (LMC) sensor technology. In addition to the sign language that is formed has diversity such as folded fingers, hidden fingers, indonesian sign forms also have characteristics and shapes that are almost similar to one another. The LMC sensor is not always able to recognize all forms of signs properly. In this study, optimization is proposed at the feature level where optimization aims to provide more detailed features and characteristics of each sign language formed. The stages of the process are designing the layout of the sensors, adding features and combining feature data from each sensor. The test of the feature optimization on this dual LMC sensor can provide an increase in the recognition accuracy of the given Indonesian sign language. The Indonesian sign language can be recognized well with an average accuracy of $87.24 \%$ and the optimization carried out is able to produce an increase in accuracy of up to $2.88 \%$.
\end{abstract}

Keyword : Sign language, Leap Motion Controller, Sensor technology

\section{Introduction}

Sign language is a language formed by a combination of finger movements, orientation of hand, arm, body movements as well as lip movements and facial expressions.Sign language communication in Indonesia is one of the sign language communications built by adopting the American Sign Language (ASL) sign language which is owned by America.Communication between persons with disabilities will certainly be very difficult for normal people to understand in general and will find it difficult to know and understand the sign language conveyed by the deaf and speech impaired.This is due to differences in methods and ways of communication, and vice versa. So we need a system that can translate the difference in communication methods between sign language communication and normal communication..

In the field of technology, of course, during the last decade many studies have been carried out and some of these sign language recognition studies have focused on the algorithms used or methods consisting of static and dynamic cues [1]. Many research works have been directed and carried out to develop the recognition of different sign languages [2]. Some of these studies are American Sign Language(ASL) [3], Malaysian Sign Language [4], Indian Sign Language (ISL) [5] and Arabic Sign Language (ArSL) [6]. Other sign language research uses an image-based and sensor-based approach, where the sign language algorithm is divided into three parts, namely recognition based on letters, words and sentences. Where the word recognition technique is to capture and analyze each continuous image that represents the whole word in sign language [7].

The development of sign language research today, of course, does not only depend on algorithms and sign recognition techniques, but researchers have also presented many of the existing sensor technologies. The combination of combined static features for static cues and dynamic features for gestures, obtained from LMC[8]. However, in practice, it is said that motion capture sensors such as Kinect and LMC cannot always recognize all fingers. Because not only fingers touching each other, but folded, hidden or blocked fingers by other fingers can cause the camera sensor to not recognize and capture properly.[9]. So it takes several other sensor sources or more than one sensor (multi sensor) to be able to minimize and overcome this. In previous studies, the results obtained from the use of dual sensors stated that the accuracy of some of these scenarios could increase sensor performance by $5.35 \%$ or with an average accuracy of $84.36 \%$.[10].

Therefore, in this study, an optimization scenario is proposed to improve the performance of sensor accuracy in recognizing signs in Indonesian Sign Language, namely by adding the characteristics or characteristics of each sign obtained. So that the use of

\footnotetext{
* Corresponding author : syaiful_ft@unmus.ac.id
} 
this scenario can optimize the detection and capture sensor process for the given hand signs and can improve the recognition accuracy of Indonesian Sign Language.

\section{Methodology}

In this section, several supporting research methodologies, research designs and the stages of research carried out are described, as follows:

\subsection{Leap Motion Controller}

The LMC system is a system that can recognize hand movements, using optical sensors and infrared light. The sensor is pointed along the $y$-axis direction when the controller is in standard operation and has a 150-degree field of view. The effective distance of the LMC extends over the device from $25-600$ millimeters $(1$ inch -2 $\mathrm{ft}$ ). The LMC can detect hands, fingers and tools that are in the LMC's field of view. Each frame object represents a frame containing a list of detection data such as hands, fingers and finger-shaped devices, as well as motion detection [11].

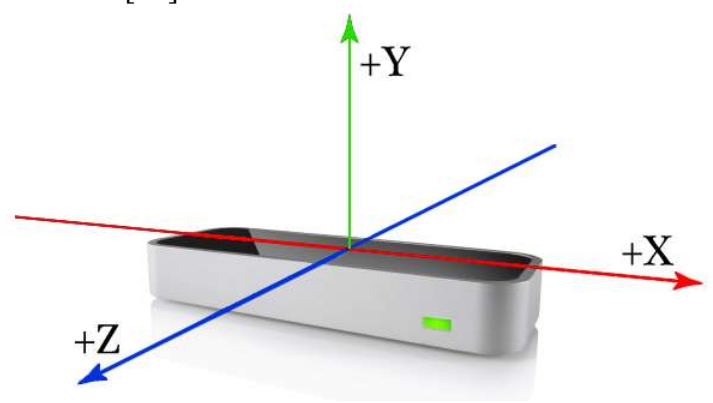

Fig. 1. Leap Motion Controller coordinate system.

\subsection{Dual Sensor Design}

The sensor layout design is used to position each sensor to be able to capture the form of a given sign language that is captured from various angles, namely 0 degrees, 90 degrees, 120 and 120 degrees.[10].
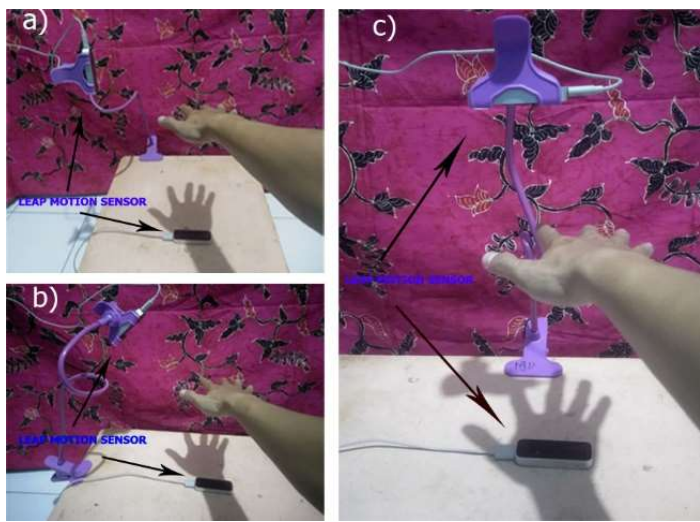

Fig. 2. LMC Sensor layout design.

\subsection{Data Collection}

A total of 26 letters of the Indonesian Sign Language alphabet as shown in Figure 3, will be tested in this study. Indonesian cues are categorized into two parts, namely static cues and dynamic cues[12]. Dynamic cues are signs given by finger or hand movements. Therefore, it is necessary to add several other features that have been selected to give the characteristics and characteristics of each class or letter. For one data recording is done using 10 frames, and each letter will be recorded ten times from the existing letters of the alphabet plus one position or normal hand condition. So the total of the data obtained is 270 datasets per scenario.

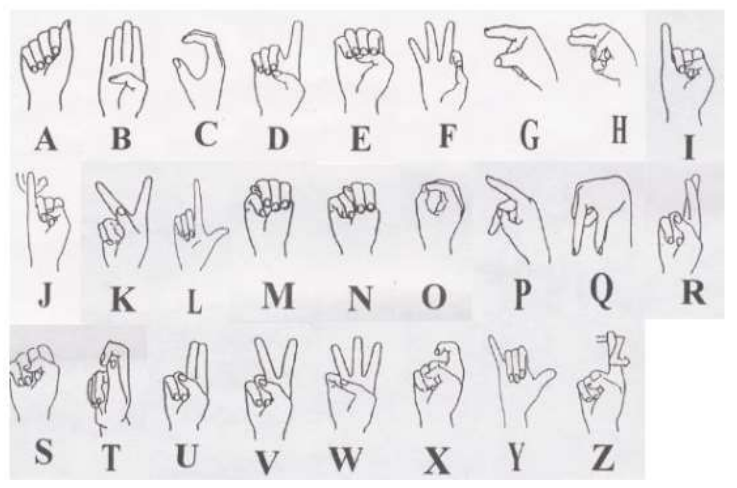

Fig. 3. Indonesian Sign Language.

\subsection{Feature Optimization}

The process carried out is the collection of samples or datasets obtained from the detection results on each LMC sensor for hand signs based on Indonesian Sign Language. The coordinate data of the sign is used as input material into the system which will be processed at a later stage. Feature extraction is the process of selecting or taking a feature and characteristic from the previously inputted sign form.

Table 1. Static and dynamic features

\begin{tabular}{|c|c|c|}
\hline Feature Name & Unit & Type \\
\hline Average Spread & $\mathrm{mm}$ & Static \\
\hline Average tri-spread & $\mathrm{mm}$ & Static \\
\hline Extended Distance & $\mathrm{mm}$ & Static \\
\hline Hand Gesture & {$[0-9]$} & Static \\
\hline
\end{tabular}

There is table 1 above are the features used in previous studies [10]. Therefore, in this study, several other features were added which aim to provide more detailed characteristics or in other words optimize the formation of features from the given signal. Table 3 below is a combination of the features added and used in this study [13]. 
Table 2. Added features

\begin{tabular}{|c|c|c|}
\hline Feature Name & Unit & Type \\
\hline Pinch Strenght & Float [0-1] & Static \\
\hline Grab Strenght & Float [0-1] & Static \\
\hline Average Distance & $\mathrm{mm}$ & Static \\
\hline
\end{tabular}

Table 3. Features Combination

\begin{tabular}{|c|c|c|}
\hline Feature Name & Unit & Type \\
\hline Average Spread & $\mathrm{mm}$ & Static \\
\hline Average tri-spread & $\mathrm{mm}$ & Static \\
\hline Extended Distance & $\mathrm{mm}$ & Static \\
\hline Hand Gesture & {$[0-9]$} & Static \\
\hline Pinch Strenght & Float [0-1] & Static \\
\hline Grab Strenght & Float [0-1] & Static \\
\hline Average Distance & $\mathrm{mm}$ & Static \\
\hline
\end{tabular}

\section{Results and Discussion}

The testing were carried out on the use of this dual sensor with the addition of the features already provided. The first scenario is to test dual LMC sensors based on the sensor layouts in Figures 2a, $2 b$ and $2 c$. The results obtained will be compared between scenarios so that the best scenario can be obtained in optimizing recognize for Indonesian sign language. In this test, the dataset is divided into training data as much as $70 \%$ of the dataset and $30 \%$ of the dataset as test data. So that the test data becomes 81 data and each class has 3 test data.

\subsection{Scenario 1}

Scenario 1 is a combination test at the feature level with reference to the layout of the two LMC sensors forming 90 degrees as shown in Figure 2a.

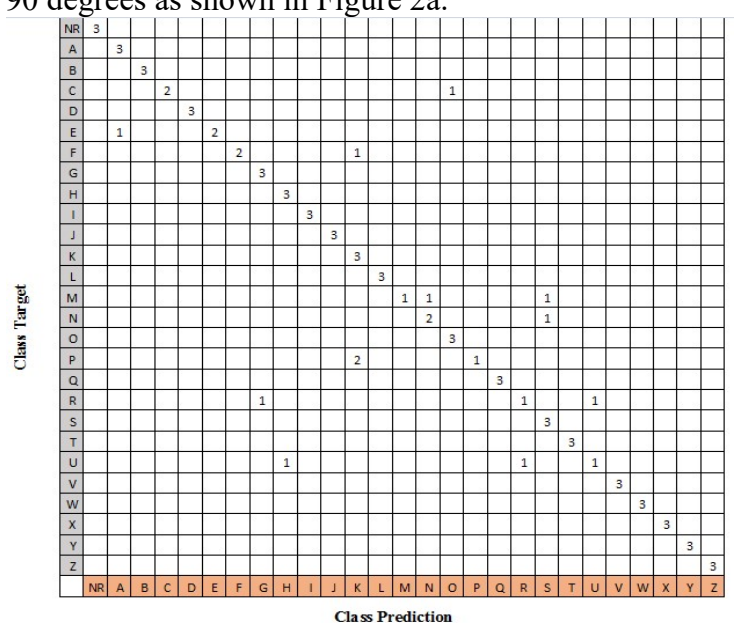

Fig. 4. Result of Scenario 1.

\subsection{Scenario 2}

Scenario 2 is a combination at the feature level with reference to the layout of the two LMC sensors forming 120 degrees as shown in Figure 2b.

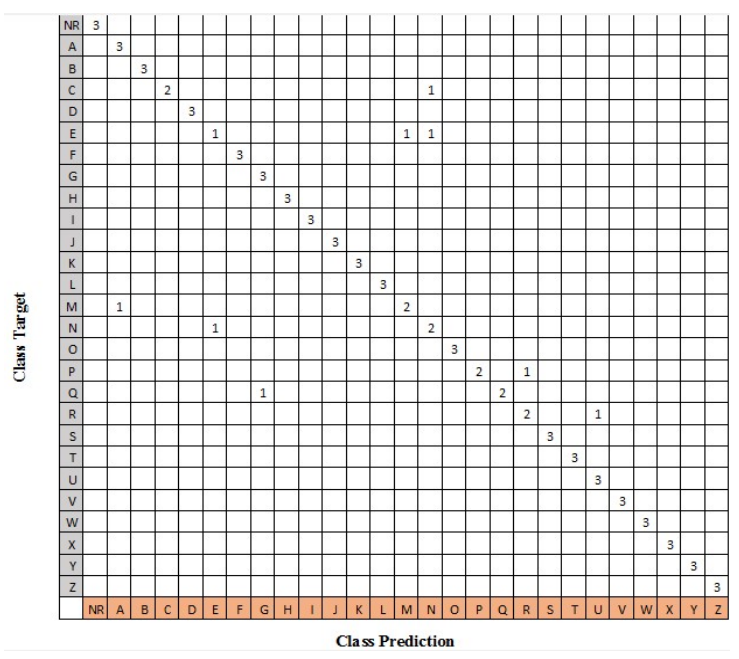

Fig. 5. Result of Scenario 2.

\subsection{Scenario 3}

Scenario 3 is a combination at the feature level with reference to the layout of the two LMC sensors forming 180 degrees or facing each other as shown in Figure 2c.

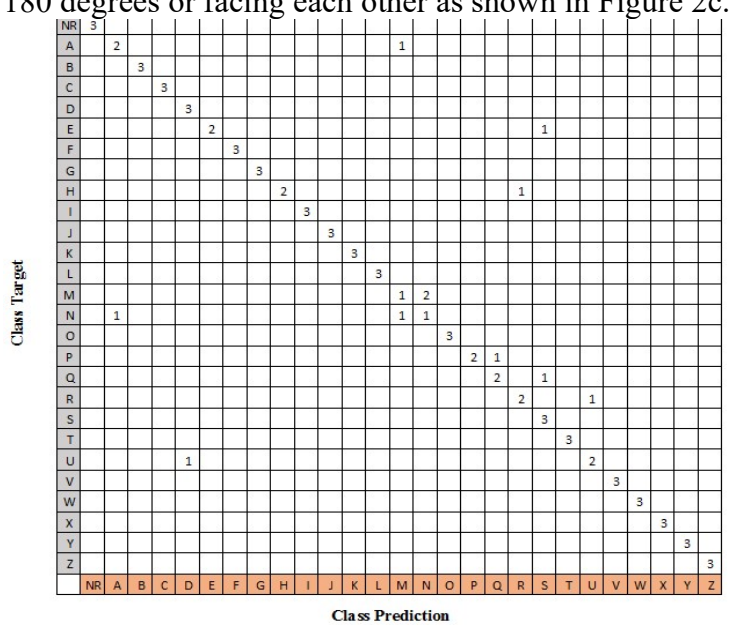

Fig. 6. Result of Scenario 3.

From the three scenarios above, the results of the recognition accuracy of the test data have been obtained from each scenario. The results obtained for each target class in each scenario are very varied. Recognition errors still occur for letters with a high degree of similarity such as E, M, N and R. However, with the addition of features made previously, it can optimize the recognition of sensors for Indonesian Sign Language. The following is a comparison chart of the accuracy of the tests carried out based on scenarios. 


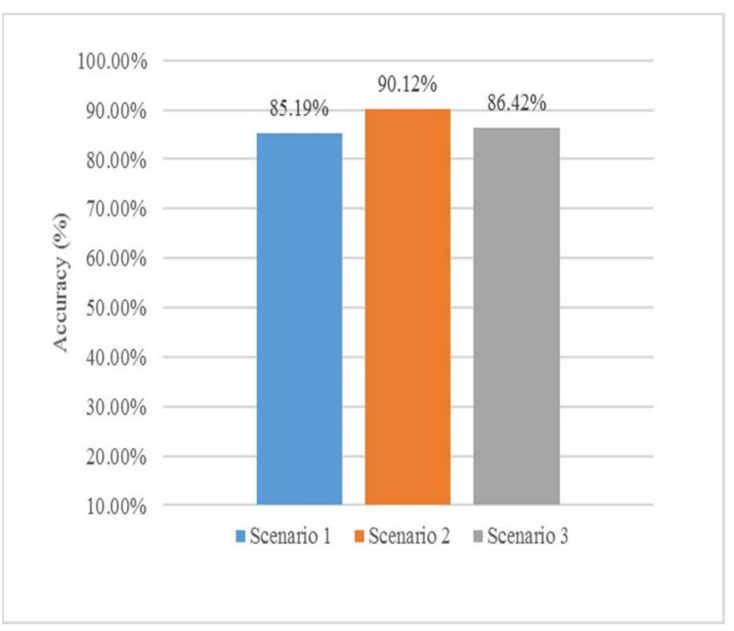

Fig. 7. Accuracy comparison chart.

The results of the tests that have been carried out, by optimizing the features of this Indonesian sign, the LMC sensor overall has a good recognition accuracy. In previous studies, it was stated that the use of dual sensors obtained an average accuracy of $84.36 \%$ from the combination of feature data and sensor layout [10]. By referring to the addition of features or characteristics of each signal form, the resulting accuracy can be increased compared to using three static features and one dynamic feature, so that in this study each class has six static features and one dynamic feature. The scenario with the highest accuracy results was obtained from the results of scenario 2, which was $90.12 \%$. Based on the analysis carried out, this can occur because the maximum sensor capture power for hand signals is sourced from two LMC sensors. Letters that have a high degree of similarity can be minimized by adding features, optimizing features for the formed signs. Therefore, the weakness of LMC which cannot recognize Indonesian language cues such as hidden, folded or blocked fingers by other fingers, can be captured optimally based on the sensor layout scenario, feature combination and feature optimization of these features.

\section{Conclusion}

The addition and selection of features in this study is very necessary to be able to increase the diversity of characteristics and characteristics of each letter, because Indonesian Sign Language has several signs that have a high similarity. After various tests were carried out and the results obtained, it can be concluded that with the design of the sensor location, combination of features and optimization through additions made to the feature level of the two LMC sensors, the Indonesian sign system can be well recognized with an average accuracy of $87.24 \%$ and the optimization carried out was able to produce an increase in accuracy results reaching $2.88 \%$.

\section{References}

1. S. Kausar and M. Y. Javed, "A Survey on Sign Language Recognition,” 2011 Front. Inf. Technol., no. October, pp. 95-98, (2011).

2. K. Y. Fok, N. Ganganath, C. T. Cheng, and C. K. Tse, "A Real-Time ASL Recognition System Using Leap Motion Sensors," Proc. - 2015 Int. Conf. Cyber-Enabled Distrib. Comput. Knowl. Discov. CyberC 2015, pp. 411-414, (2015).

3. C. Oz and M. C. Leu, "Linguistic properties based on American Sign Language isolated word recognition with artificial neural networks using a sensory glove and motion tracker," Neurocomputing, vol. 70, no. 7, pp. 2891-2901, (2007).

4. A. Z. Shukor, M. F. Miskon, M. H. Jamaluddin, F. Bin Ali Ibrahim, M. F. Asyraf, and M. B. Bin Bahar, "A New Data Glove Approach for Malaysian Sign Language Detection," Procedia Comput. Sci., vol. 76, no. Iris, pp. 60-67, (2015).

5. P. Das, R. De, S. Paul, M. Chowdhury, and B. Neogi, "ANALYTICAL STUDY AND OVERVIEW ON GLOVE BASED INDIAN SIGN LANGUAGE INTERPRETATION," pp. 313-318, (2015).

6. M. Mohandes and M. Deriche, "Arabic sign language recognition by decisions fusion using Dempster-Shafer theory of evidence," 2013 Comput. Commun. IT Appl. Conf., pp. 90-94, (2013).

7. M. Mohandes, S. Aliyu, and M. Deriche, “Arabic sign language recognition using the leap motion controller," 2014 IEEE 23rd Int. Symp. Ind. Electron., pp. 960-965, (2014).

8. Supria, D. Herumurti, and K. Wijayanti Nurul, "Pengenalan sistem isyarat bahasa indonesia menggunakan kombinasi fitur statis dan fitur dinamis LMC berbasis L-GCNN," JUTI - J. Teknol. Infomasi, vol. 14, no. 2, pp. 217-230, (2016).

9. G. Marin, F. Dominio, and P. Zanuttigh, "Hand gesture recognition with leap motion and kinect devices," 2014 IEEE Int. Conf. Image Process. ICIP 2014, pp. 1565-1569, (2014).

10. S. Nugraha, D. H. Murti, and W. N. Khotimah, "Penggunaan Dual Sensor Leap Motion Controller untuk Sistem Isyarat Bahasa Indonesia," Inform. J., vol. 4, no. 2, pp. 48-58, (2019).

11. Hariyanto, R. Sarno, and D. R. Wijaya, "2017 International Conference on Information \& Communication Technology and System (ICTS)," Detect. Diabetes from Gas Anal. Hum. Breath using E-Nose, vol. 0, pp. 241-246, (2017).

12. W. Khotimah, R. Saputra, N. Suciati, and R. Hariadi, "Alphabet Sign Language Recognition Using Leap Backpropagation-Genetic Algorithm Neural,” J. Ilm. Teknol. Inf., vol. 15, pp. 95-103, (2017). 
13. C. Chuan, E. Regina, C. Guardino, A. L. M. Controller, and I. Apis, “American Sign Language Recognition Using Leap Motion Sensor,” pp. 541544, (2014). 